\title{
Analytical Method Development and Validation of Solifenacin in Pharmaceutical Dosage Forms by RP-HPLC
}

\author{
Rihana Parveen Shaik, ${ }^{1,2}$ Srinivasa Babu Puttagunta, ${ }^{1}$ Chandrasekar Kothapalli Bannoth, ${ }^{2}$ \\ and Bala Sekhara Reddy Challa ${ }^{3}$
}

\author{
${ }^{1}$ Vignan Pharmacy College, Vadlamudi, Guntur, Andhra Pradesh 522213, India \\ ${ }^{2}$ Jawaharlal Nehru Technological University Anantapur, Andhra Pradesh 515002, India \\ ${ }^{3}$ Vaagdevi College of Pharmacy, Gurazala, Guntur, Andhra Pradesh 522415, India \\ Correspondence should be addressed to Rihana Parveen Shaik; rihanaparveen@gmail.com
}

Received 4 January 2014; Accepted 12 February 2014; Published 16 April 2014

Academic Editors: J. Esteve-Romero and A. Tsantili-Kakoulidou

Copyright (C) 2014 Rihana Parveen Shaik et al. This is an open access article distributed under the Creative Commons Attribution License, which permits unrestricted use, distribution, and reproduction in any medium, provided the original work is properly cited.

\begin{abstract}
A new, accurate, precise, and robust HPLC method was developed and validated for the determination of solifenacin in tablet dosage form. The chromatographic separation was achieved on an Inertsil ODS $3 \mathrm{~V} \mathrm{C}_{18}(150 \mathrm{~mm} \times 4.6 \mathrm{~mm}, 5 \mu \mathrm{m})$ stationary phase maintained at ambient temperature with a mobile phase combination of monobasic potassium phosphate (pH 3.5) containing $0.1 \%$ triethylamine and methanol (gradient mode) at a flow rate of $1.5 \mathrm{~mL} / \mathrm{min}$, and the detection was carried out by using UV detector at $220 \mathrm{~nm}$. The performance of the method was validated according to the present ICH guidelines.
\end{abstract}

\section{Introduction}

Solifenacin succinate is a competitive muscarinic acetylcholine receptor antagonist used in the treatment of overactive bladder with or without urge incontinence. Chemically it is 1-azabicyclo[2.2.2] oct-8-yl(1S)-1-phenyl-3,4-dihydro-1Hisoquinoline-2 carboxylate shown in Figure 1.

The molecular formula of solifenacin succinate is $\mathrm{C}_{23} \mathrm{H}_{26} \mathrm{~N}_{2} \mathrm{O}_{2}$ with its molecular weight 362.46 . Solifenacin is extensively metabolized in the liver. The metabolites observed as one pharmacologically active metabolite (4Rhydroxy solifenacin), and three pharmacologically inactive metabolites ( $\mathrm{N}$-glucuronide and the $\mathrm{N}$-oxide and 4R-hydroxy-N-oxide of solifenacin) occurring at low concentrations in human plasma after oral dosing. After oral administration of vesicare to healthy volunteers, peak plasma levels (Cmax) of solifenacin are reached within 3 to 8 hours after administration and at steady state ranged from 32.3 to $62.9 \mathrm{ng} / \mathrm{mL}$ for the 5 and $10 \mathrm{mg}$ vesicare tablets, respectively. The terminal elimination half-life of SF is approximately 45-68 hours. Solifenacin is approximately 98\% (in vivo) bound to human plasma proteins, principally to alpha-1-acid glycoprotein [1-10].
Literature survey reveals that quantification of solifenacin in human plasma [11, 12], rat plasma [13], pharmaceutical compounds [14-17], and industrial waste streams [18] was reported. These methods were reported by using LC-MS/MS $[11,12,18]$, HPLC [13-16], and HPTLC [17]. Among all, quantification of solifenacin by LC-MS/MS in biological matrices [11-13] was proved best results.

The reported HPLC methods [13-16] have some drawbacks in terms of ruggedness, reproducibility, and sensitivity in long run. The main goal of the present study is to develop and validate the novel simple, higher sensitive, selective, rugged, and reproducible analytical method for quantitative determination of solifenacin in pharmaceutical compounds by HPLC. The developed method would be applied in finished product and in quality control.

\section{Experimental}

2.1. Instrumentation. The Waters HPLC system equipped with autosampler and UV or DAD was used for method development and method validation. The output signal was monitored and processed by using Empower software. 
TABLE 1: Gradient program.

\begin{tabular}{lcccc}
\hline \multicolumn{4}{c}{ Mobile phase gradient program } \\
Time (min) & A\% & B\% & $\begin{array}{c}\text { Flow rate } \\
\text { (mL/min) }\end{array}$ & $\begin{array}{c}\text { Gradient } \\
\text { program }\end{array}$ \\
\hline 0.00 & 50 & 50 & 1.5 & Initial \\
8.00 & 30 & 70 & 1.5 & Linear \\
8.5 & 15 & 85 & 1.5 & Linear \\
13.0 & 15 & 85 & 1.5 & Isocratic \\
13.1 & 50 & 50 & 1.5 & Linear \\
16.0 & 50 & 50 & 1.5 & Isocratic \\
\hline
\end{tabular}

2.2. Materials. Solifenacin succinate bulk drug was made available from Genova Labs, Bangalore; orthophosphoric acid (85\%), potassium phosphate monobasic, methanol, and acetonitrile were obtained from Merk. Commercially available solifenacin tablets were used for the dosage form analysis. All chemicals and reagents used were of HPLC grade; Milli-Q-water was used throughout the experiment. The pharmaceutical dosage form assayed in the study is test formulation containing $5 \mathrm{mg}$ of solifenacin.

\subsubsection{Mobile Phase Preparation}

Solution A. About $1.36 \mathrm{~g}$ of potassium phosphate monobasic was dissolved into $1000 \mathrm{~mL}$ of water. Then $1 \mathrm{~mL}$ of triethylamine was added and mixed well. Finally $\mathrm{pH} 3.5 \pm 0.05$ adjusted with orthophosphoric acid (85\%) was mixed and degas-filtered.

Solution B. This contained methanol. Gradient program was shown in Table 1.

Sample Solvent. This contained mobile phase A : B: $20: 80$ (\% $\mathrm{v} / \mathrm{v})$.

2.3. Chromatographic Conditions. The mobile phase used was mixture of monobasic potassium phosphate containing $0.1 \%$ triethylamine and methanol in the ratio of gradient elution at a flow rate of $1.5 \mathrm{~mL} / \mathrm{min}$ and the injection volume was $10 \mu \mathrm{L}$. The analytical column used was Inertsil ODS $3 V C_{18}(150 \mathrm{~mm}$ $\times 4.6 \mathrm{~mm}, 5 \mu \mathrm{m})$ at ambient temperature. The detection was carried out at a wavelength of $220 \mathrm{~nm}$ for a run time of $16 \mathrm{~min}$. The retention time of solifenacin was found to be $5.12 \mathrm{~min}$.

2.4. Preparation of Standard Stock Solution. Accurately weigh and transfer $50 \mathrm{mg}$ of solifenacin succinate working standard into two separate $100 \mathrm{~mL}$ clean dry volumetric flasks; add diluent and sonicate to dissolve it completely and make up volume to the mark with the same solvent (sample solvent solution). Further pipette $10.0 \mathrm{~mL}$ solifenacin of the above stock solution into a $50 \mathrm{~mL}$ volumetric flask and dilute it up to the mark with diluent.
TABLE 2

\begin{tabular}{ll}
\hline $\begin{array}{l}\text { Assay } \\
(\mathrm{mg} / \mathrm{g})\end{array}$ & $\begin{array}{l}A_{\mathrm{Sa}} \times \text { standard weight } \times \text { sample dilution } \times \% \mathrm{P} \times 1000 \\
A_{\mathrm{Std}} \times \text { standard dilution } \times \text { sample weight } \times 100\end{array}$ \\
\hline $\begin{array}{l}\text { Assay } \\
(\%)\end{array}$ & Assay $(\mathrm{mg} / \mathrm{g}) \times 100$ \\
\hline Tabel & $A_{\mathrm{Sb}} \times$ standard weight $\times$ sample dilution $\times \% \mathrm{P} \times 100$ \\
claim $(\%)$ & $A_{\mathrm{Std}} \times$ standard dilution $\times N \times 100 \times \mathrm{LC}$ \\
\hline$A_{\mathrm{Sa}}:$ area of sample in blend assay. \\
$A_{\mathrm{Sb}}:$ area of sample in drug product assay. \\
$A_{\mathrm{Std}}:$ mean area of standard. \\
Spl: drug substance sample for assay. \\
Spt: drug substance standard for assay. \\
$\% \mathrm{P}:$ percentage of potency (as is basis). \\
LC: label claim in mg.
\end{tabular}

2.4.1. Assay of Pharmaceutical Dosage Form: Sample Preparation. Take 20 tablets and calculate the average weight. Crush the tablets and accurately weigh $50 \mathrm{mg}$ of tablet powder and transfer it into $100 \mathrm{~mL}$ volumetric flask and add sample solvent to extract solifenacin by ultrasonication for $10 \mathrm{~min}$. The resultant mixture was filtered through $0.45 \mu$ filter. From this, take $10.0 \mathrm{~mL}$ and transfer it to $50 \mathrm{~mL}$ volumetric flask and make up the volume using mobile phase as shown in Table 2.

\section{Results and Discussion}

3.1. Optimization of Chromatographic Conditions. Several HPLC methods were developed for the estimation of solifenacin using methanol, water, acetonitrile and phosphate, acetate, and OPA buffer. Hence we have selected potassium phosphate buffer and Inertsil ODS $3 \mathrm{~V} \mathrm{C}_{18}(150 \mathrm{~mm} \times 4.6 \mathrm{~mm}$, $5 \mu \mathrm{m}$ ) column to decrease the retention time and to obtain symmetric peaks having good resolution. Different trails were performed using different proportions of potassium phosphate buffer having different $\mathrm{pH}$ with methanol and acetonitrile. The mobile phase containing monobasic potassium phosphate $\mathrm{pH} 3.5$ containing $0.1 \%$ triethylamine and methanol (adjusted to $\mathrm{pH}$ 3.5): (gradient programme) was found to be satisfactory and gave symmetric and wellresolved peak for solifenacin.

The retention time of solifenacin was found to be 5.12. The USP plate count and tailing factor were 6984 and 1.34 for solifenacin. The standard chromatogram was shown in Figure 2.

3.2. Validation of Proposed Method. The proposed method was validated according to the International Conference on Harmonization (ICH) guidelines [19].

3.3. Linearity. Linearity test solutions of solifenacin (10$100(\mu \mathrm{g} / \mathrm{mL}))$ were prepared from the stock solution at five different concentration levels. The calibration curves were constructed by plotting peak areas versus their corresponding concentrations. The slope, $Y$-intercept, and correlation coefficient of the calibration curve were calculated. The correlation coefficient was found to be 0.999 and the calibration curve for solifenacin is given in Figure 3 . 
TABle 3: Precision data.

\begin{tabular}{lcc}
\hline S. No. & Precision & Intermediate Precision \\
\hline 1 & 37914 & 36524 \\
2 & 36523 & 37548 \\
3 & 37254 & 36325 \\
4 & 37023 & 35698 \\
5 & 36955 & 36324 \\
\hline Average & 37134 & 36484 \\
Standard deviation & 510.02 & 671.26 \\
\%RSD & $\mathbf{1 . 3 7}$ & $\mathbf{1 . 8 4}$ \\
\hline
\end{tabular}<smiles>O=C(O[C@H]1CN2CCC1CC2)N1CCc2ccccc2C1c1ccccc1</smiles>

FIgURE 1: Chemical structures of solifenacin.

3.4. Precision. Precision was evaluated by injecting five replicate injections of solifenacin of standard concentration under the same chromatographic conditions and calculated by the $\%$ RSD. The \%RSD indicates that the developed method is repeatable. The \%RSD for assay of solifenacin was found to be 1.37. The results are shown in Table 3 .

3.5. Intermediate Precision/Ruggedness. The intermediate precision of the method was checked by determining precision on the same instrument, using the same chromatographic conditions in different day. The \%RSD of solifenacin was found to be below 2 even when it is performed in different day. The method is said to be precise with respect to the criteria of the intermediate precision. The results are given in Table 3.

3.6. Accuracy. In order to judge the quality and applicability of method the recovery analysis was performed at three levels $50 \%, 100 \%$, and $150 \%$ by standard addition method. The $\%$ recoveries for solifenacin were calculated by injecting the samples and it was found to be within the limits; the results are given in Table 4 .

3.6.1. Robustness. The robustness as a measure of method capability to remain unaffected by small, but deliberate changes in chromatographic conditions was studied by testing influence of small changes in mobile phase composition (10\% absolute change in organic phase) and flow rate $( \pm 0.2 \mathrm{~mL} / \mathrm{min})$. The USP plate count and USP tailing were within the limits. So, the method was found to be robust with respect to variability in all robust conditions.

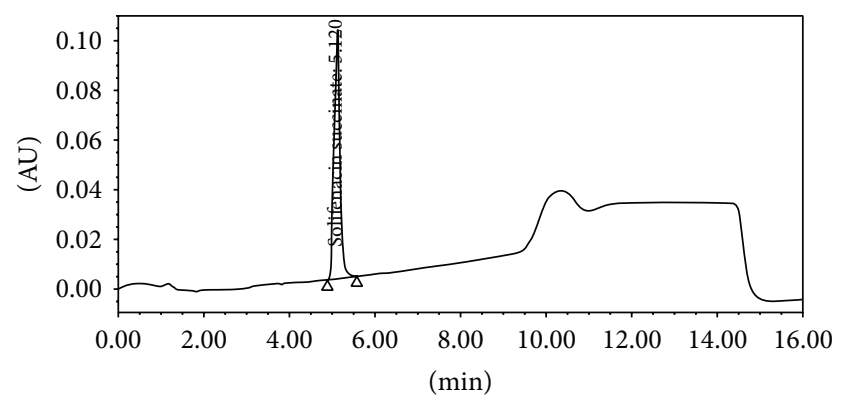

FIGURE 2: HPLC chromatogram of standard solifenacin.

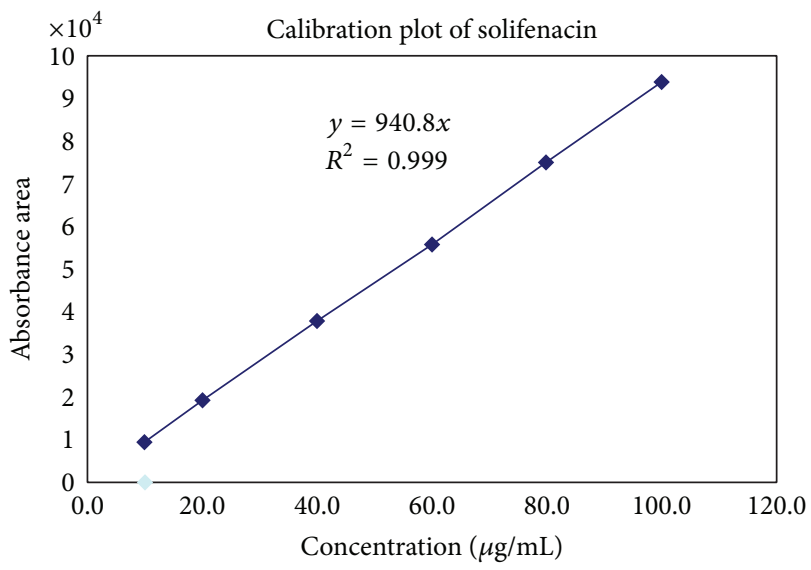

FIGURE 3: Calibration curve of solifenacin.

3.6.2. $L O D$ and $L O Q$. The $L O D$ and $L O Q$ of solifenacin were determined by using the signal to noise approach as defined in ICH guidelines. The concentration with signal to noise ratio of LOD and LOQ at $\mathrm{S} / \mathrm{N}$ was 3 and 10 , respectively. The results are given in Table 5.

3.6.3. Assay of Pharmaceutical Formulation. The proposed validated method was successfully applied to determine solifenacin in its tablet dosage form. The result obtained for solifenacin was comparable with the corresponding labeled amounts and they are given in Table 6.

\section{Conclusion}

The present work refers to the fact that the most accurate, precise, and robust HPLC method was developed and validated for estimation of solifenacin in pharmaceutical dosage form in accordance with the ICH parameters. The method was validated and found to be simple, accurate, and precise. Percentage of recovery shows that the method is free from interference of the excipients used in the formulation. Therefore, the proposed method can be used for routine analysis of solifenacin in its dosage form. 
TABle 4: Accuracy data.

\begin{tabular}{lccccc}
\hline Analyte & \% Level & Nominal value $(\mathrm{mg})$ & Found $(\mathrm{mg})$ & \% Recovery & Mean \% Recovery \\
\hline \multirow{3}{*}{ Solifenacin } & $50 \%$ & 2.5 & 2.35 & 94.00 & 9.60 \\
& $100 \%$ & 5 & 4.98 & 9.60 & 95.38 \\
& $150 \%$ & 7.5 & 6.94 & 92.53 \\
\hline
\end{tabular}

TABLE 5: LOD and LOQ.

\begin{tabular}{ccccc}
\hline & $\begin{array}{c}\text { LOD } \\
(\mu \mathrm{g} / \mathrm{mL})\end{array}$ & $\begin{array}{c}\text { LOQ } \\
(\mu \mathrm{g} / \mathrm{mL})\end{array}$ & $\begin{array}{c}\text { LOD } S / N \\
\text { Ratio }\end{array}$ & $\begin{array}{c}\text { LOQ } S / N \\
\text { Ratio }\end{array}$ \\
\hline Solifenacin & 0.02 & 10.00 & 3.14 & 14.16 \\
\hline
\end{tabular}

TABLE 6: Assay Results.

\begin{tabular}{cccc}
\hline & Label Claim $(\mathrm{mg})$ & Amount found $(\mathrm{mg})$ & $\%$ Assay \\
\hline Solifenacin & 5.0 & 4.85 & 97.00 \\
\hline
\end{tabular}

\section{Conflict of Interests}

The authors declare that there is no conflict of interests regarding the publication of this paper.

\section{Acknowledgment}

The authors are very thankful to Adcock Ingram, Genova Research Labs, Bangalore, for providing facilities and equipment and for providing samples.

\section{References}

[1] F. J. Morales-Olivas and L. Estañ, "Solifenacin pharmacology," Archivos Espanoles de Urologia, vol. 63, no. 1, pp. 43-52, 2010.

[2] O. Doroshyenko and U. Fuhr, "Clinical pharmacokinetics and pharmacodynamics of solifenacin," Clinical Pharmacokinetics, vol. 48 , no. 5, pp. 281-302, 2009.

[3] S. Hoffstetter and C. L. Fah, "Solifenacin succinate for the treatment of overactive bladder," Expert Opinion on Drug Metabolism and Toxicology, vol. 5, no. 3, pp. 345-350, 2009.

[4] M. E. Kuipers, W. J. J. Krauwinkel, H. Mulder, and N. Visser, "Solifenacin demonstrates high absolute bioavailability in healthy men," Drugs in R and D, vol. 5, no. 2, pp. 73-81, 2004.

[5] U. L. Roberti Maggiore, S. Salvatore, F. Alessandri et al., "Pharmacokinetics and toxicity of antimuscarinic drugs for overactive bladder treatment in females," Expert Opinion on Drug Metabolism and Toxicology, vol. 8, no. 11, pp. 1387-1408, 2012.

[6] T. Uchida, W. J. Krauwinkel, H. Mulder, and R. A. Smulders, "Food does not affect the pharmacokinetic of solifenacin, a new muscarinic receptor antagonist: results of a randomized crossover trial," British Journal of Clinical Pharmacology, vol. 58, no. 1, pp. 4-7, 2004.

[7] S. Yamada, S. Kuraoka, A. Osano, and Y. Ito, "Characterization of bladder selectivity of antimuscarinic agents on the basis of in vivo drug-receptor binding," International Neurourology Journal, vol. 16, no. 3, pp. 107-115, 2012.
[8] S. Maruyama, H. Tsukada, S. Nishiyama et al., "In vivo quantitative autoradiographic analysis of brain muscarinic receptor occupancy by antimuscarinic agents for overactive bladder treatment," Journal of Pharmacology and Experimental Therapeutics, vol. 325, no. 3, pp. 774-781, 2008.

[9] M. Kuipers, R. Smulders, W. Krauwinkel, and T. Hoon, "Openlabel study of the safety and pharmacokinetics of solifenacin in subjects with hepatic impairment," Journal of Pharmacological Sciences, vol. 102, no. 4, pp. 405-412, 2006.

[10] E. Callegari, B. Malhotra, P. J. Bungay et al., "A comprehensive non-clinical evaluation of the CNS penetration potential of antimuscarinic agents for the treatment of overactive bladder," British Journal of Clinical Pharmacology, vol. 72, no. 2, pp. 235246, 2011.

[11] J. Macek, P. Ptacek, and J. Klima, "Determination of solifenacin in human plasma by liquid chromatography-tandem mass spectrometry," Journal of Chromatography B: Analytical Technologies in the Biomedical and Life Sciences, vol. 878, no. 31, pp. 33273330, 2010.

[12] H. N. Mistri, A. G. Jangid, A. Pudage, D. M. Rathod, and P. S. Shrivastav, "Highly sensitive and rapid LC-ESI-MS/MS method for the simultaneous quantification of uroselective $\alpha 1$-blocker, alfuzosin and an antimuscarinic agent, solifenacin in human plasma," Journal of Chromatography B: Analytical Technologies in the Biomedical and Life Sciences, vol. 876, no. 2, pp. 236-244, 2008.

[13] T. Yanagihara, T. Aoki, Y. Soeishi, T. Iwatsubo, and H. Kamimura, "Determination of solifenacin succinate, a novel muscarinic receptor antagonist, and its major metabolite in rat plasma by semi-micro high performance liquid chromatography," Journal of Chromatography B: Analytical Technologies in the Biomedical and Life Sciences, vol. 859, no. 2, pp. 241-245, 2007.

[14] S. R. Krishna, B. M. Rao, and N. S. Rao, "A validated rapid stability-indicating method for the determination of related substances in Solifenacin Succinate by ultra-fast liquid chromatography," Journal of Chromatographic Science, vol. 48, no. 10, pp. 807-810, 2010.

[15] D. Desai, G. Patel, N. Shukla, and S. Rajput, "Development and validation of stability-indicating HPLC method for solifenacin succinate: isolation and identification of major base degradation product," Acta Chromatographica, vol. 24, no. 3, pp. 399-418, 2012.

[16] B. V. Rami Reddy, B. Srinivasa Reddy, N. V. V. S. S. Raman, K. S. Reddy, and C. Rambabu, "Development and validation of a specific stability indicating high performance liquid chromatographic methods for related compounds and assay of solifenacin succinate," Journal of Chemistry, vol. 2013, Article ID 412353, 10 pages, 2013.

[17] D. J. Desai, G. Patel, D. Ruikar, R. A. Jain, and S. J. Rajput, "Development and validation of stability-indicating HPTLC 
method of solifenacin succinate," Asian Journal of Pharmaceutical and Biological Research, vol. 1, no. 3, pp. 310-316, 2011.

[18] A. M. Deegan, M. Cullen, M. Oelgemöller, K. Nolan, J. Tobin, and A. Morrissey, "A SPE-LC-MS/MS method for the detection of low concentrations of pharmaceuticals in industrial waste streams," Analytical Letters, vol. 44, no. 17, pp. 2808-2820, 2011.

[19] ICH Guidelines, "Validation of analytical procedures: text and methodology," ICH Q2(R1), 2005. 

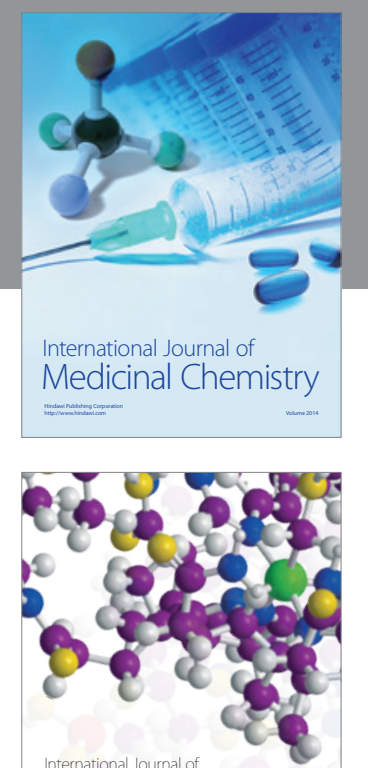

\section{Carbohydrate} Chemistry

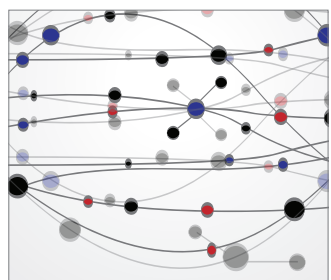

The Scientific World Journal
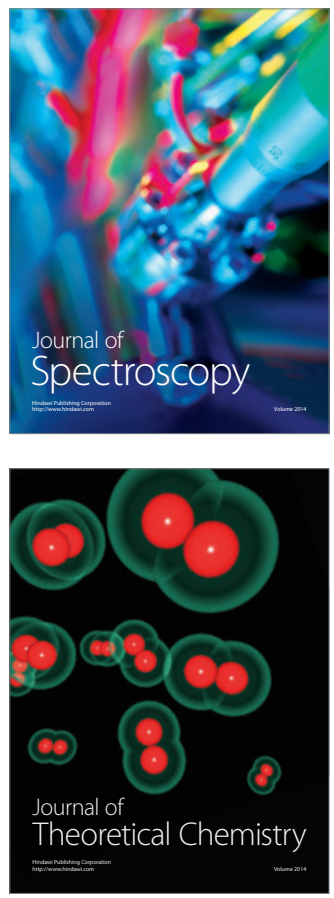
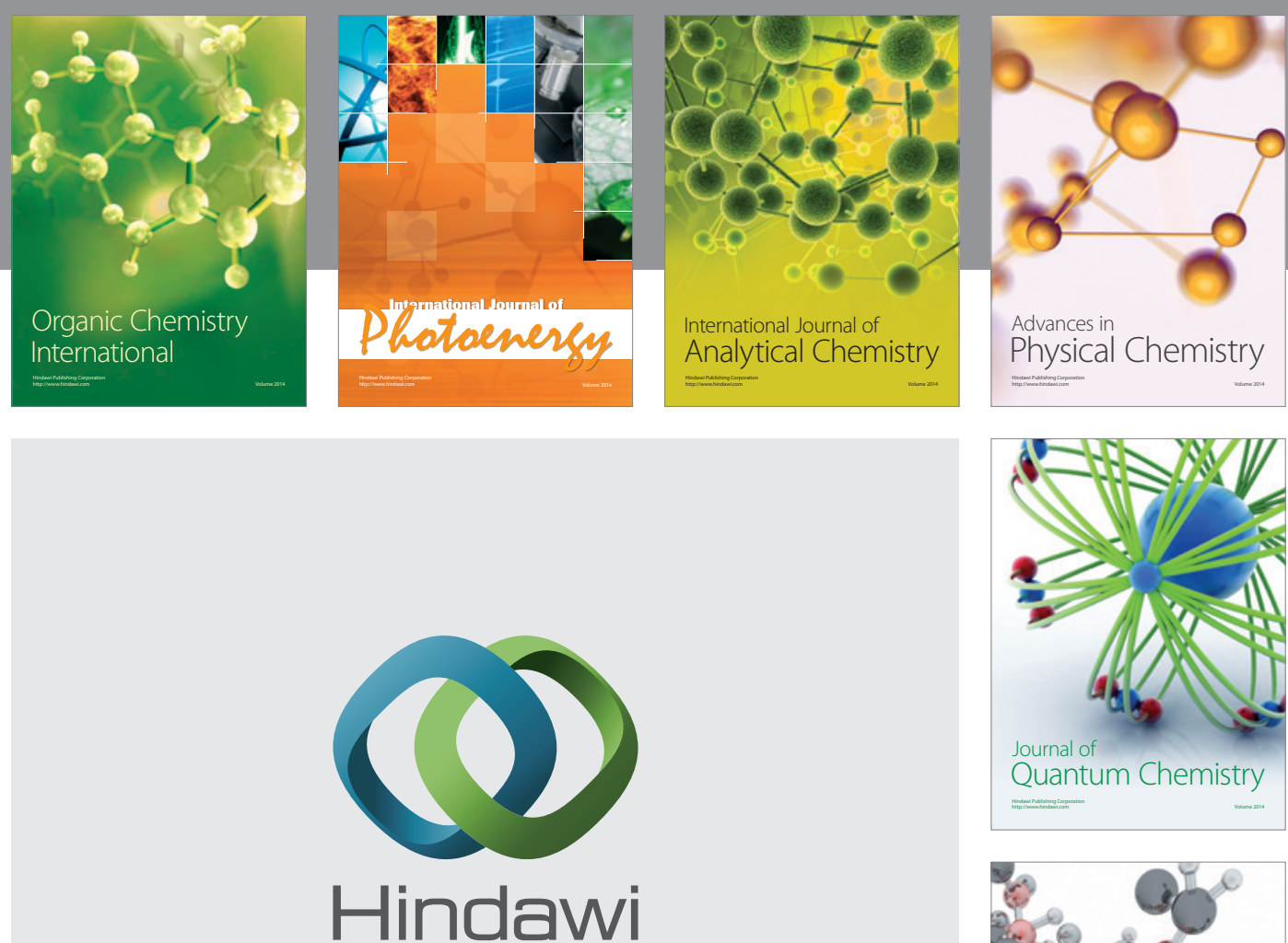

Submit your manuscripts at

http://www.hindawi.com

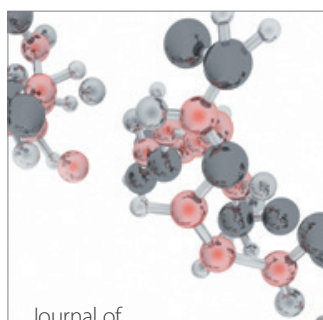

Analytical Methods

in Chemistry

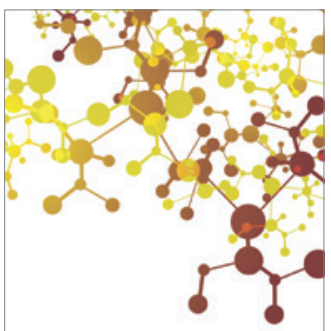

Journal of

Applied Chemistry

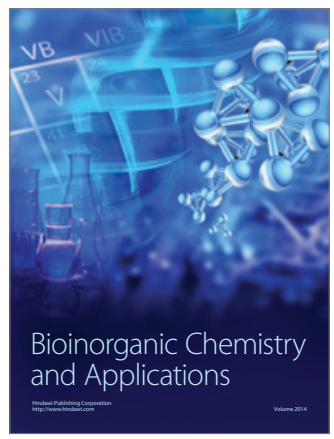

Inorganic Chemistry
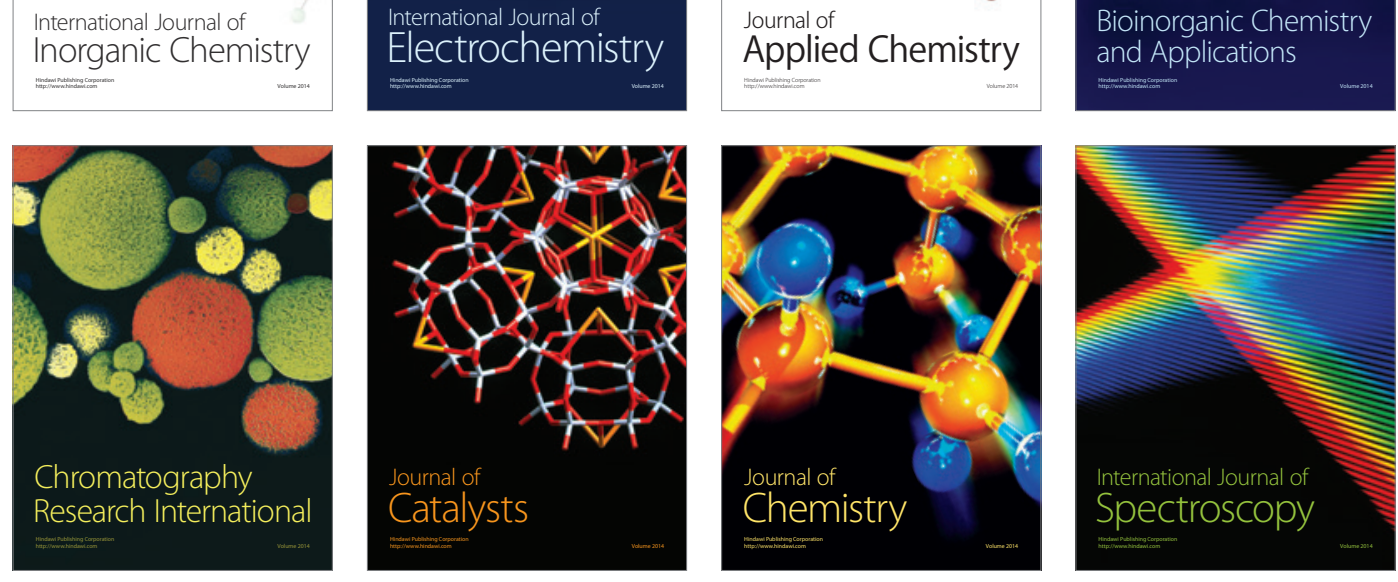